\title{
Vertical structure of orographic precipitating clouds observed over south Asia during summer monsoon season
}

\author{
Shailendra Kumar* and G S Bhat \\ Centre for Atmospheric and Oceanic Sciences (CAOS), Indian Institute of Science, Bengaluru 560 012, India. \\ ${ }^{*}$ Corresponding author.e-mail: shailendrak89@gmail.com
}

MS received 19 March 2016; revised 29 May 2017; accepted 30 May 2017; published online 23 November 2017

Orography profoundly influences seasonal rainfall amount in several places in south Asia by affecting rain intensity and duration. One of the fundamental questions concerning orographic rainfall is nature of the associated precipitating clouds in the absence of synoptic forcing. It is believed that these clouds are not very deep, however, there is not much information in the literature on their vertical structure. The present study explores the vertical structure of precipitating clouds associated with orographic features in south Asia using data collected with the precipitation radar on board the Tropical Rainfall Measuring Mission satellite. Two types of precipitating clouds have been defined based on cloud echo top height, namely, shallow echo-top cloud and medium echo-top cloud. In both, radar reflectivity factor is at least $30 \mathrm{dBZ}$ at $1.5 \mathrm{~km}$ altitude, and tops of shallow and medium echo-top clouds lie below $4.5 \mathrm{~km}$ and between 4.5 and $8 \mathrm{~km}$, respectively. The Western Ghats contains the highest fraction of the shallow echo-top clouds followed by the adjacent eastern Arabian Sea, while the Khasi Hills in Meghalaya and Cardamom Mountains in Cambodia contain the least fraction of them. Average vertical profiles of shallow echo-top clouds are similar in different mountainous areas while regional differences are observed in the medium echo-top clouds. Below $3 \mathrm{~km}$, precipitation liquid water content in medium echo-top clouds is the highest over the Western Ghats and the eastern Arabian Sea. The average precipitation liquid water content increases by $0.16 \mathrm{gm} \mathrm{m}^{-3}$ for shallow echo-top clouds between 3 and $1.5 \mathrm{~km}$ altitude, while the corresponding increase for medium echo-top clouds is in $0.05-0.08 \mathrm{gm} \mathrm{m}^{-3}$ range.

Keywords. Shallow clouds; mixed phase clouds; TRMM PR; Western Ghats; radar reflectivity.

\section{Introduction}

Several areas in south Asia get more than $200 \mathrm{~cm}$ rainfall during June-September, all anchored to or around orographic features (figure 1). The Indian west coast (IWC), Western Ghats (WG) and Khasi Hills (KH) in Meghalaya (Cherrapunji, one of the wettest places on Earth) have been known for heavy seasonal precipitation since long (Sarker 1967; Rao 1976), whereas, high rainfall areas over the eastern Bay of Bengal bordering the
Myanmar coast (MC) and the Myanmar mountains (MM) came into prominence after the high spatio-temporal resolution precipitation data from payloads on board the TRMM (Tropical Rainfall Measuring Mission) satellite became available (Xie et al. 2006; Romatschke and Houze 2011; Kumar et al. 2013; Shrestha et al. 2015; Houze et al. 2015). Among the high rainfall regions in south Asia, the Western Ghats area has been explored in some detail using observational data (Rao 1976; Mukherjee et al. 1978; Maheskumar et al. 2014) 


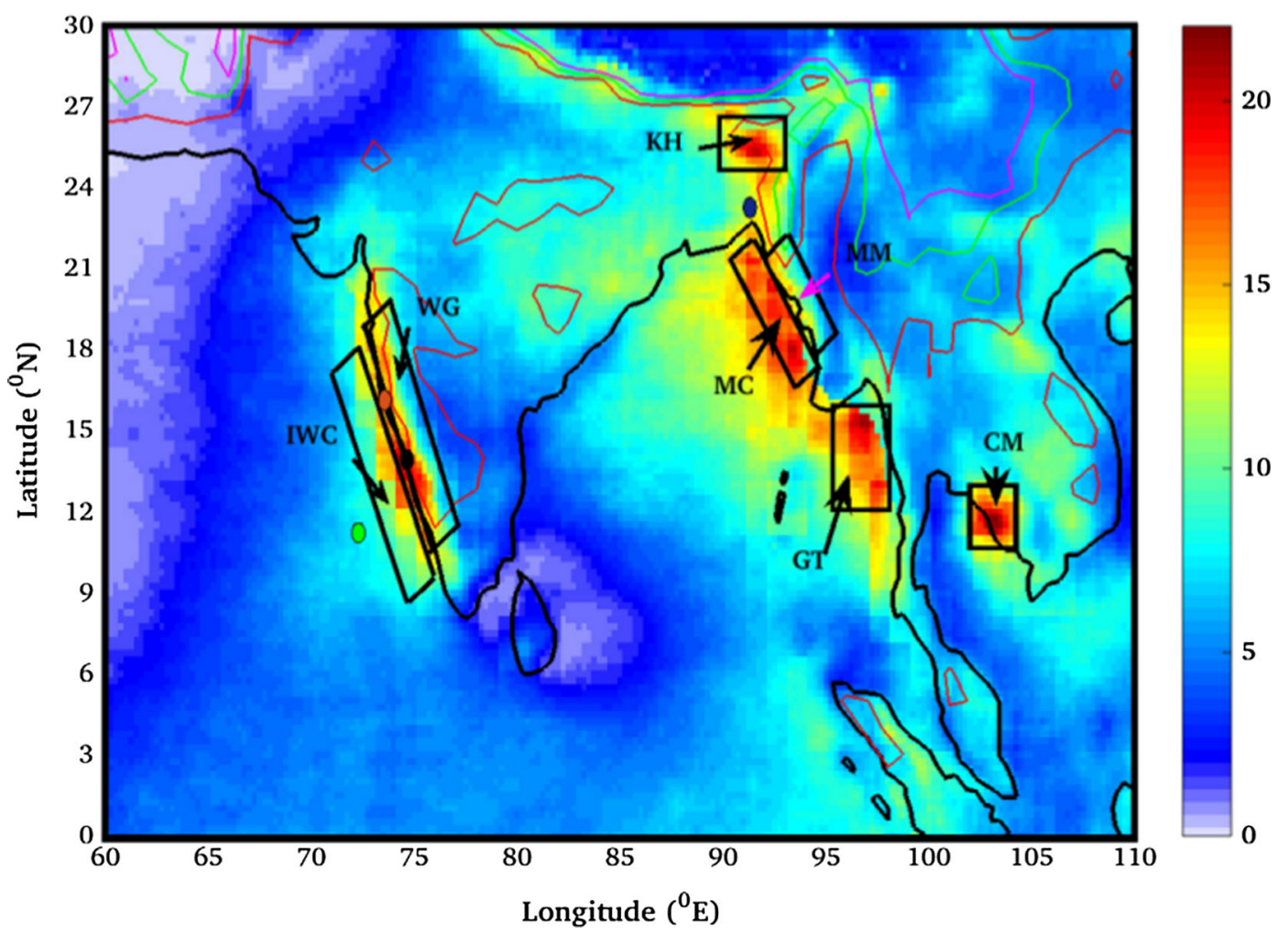

Figure 1. Daily average rainfall derived from TRMM 3B42 product for the June-September period of 2001-2010. The colour shades show rainfall amount in $\mathrm{mm} \mathrm{d}^{-1}$. Quadrilaterals show the areas selected for detailed analysis. The nomenclature is defined as, WG: Western Ghats; IWC: Indian West Coast; MM: Myanmar mountains; KH: Khasi Hills; CM: Cardamom mountains; GT: Gulf of Thailand; MC: Myanmar coast. Four upper air stations selected for analyzing relative humidity field are shown by solid circles. Colour for different stations are: lime: Aminidevi, black: Mangalore, orange: Goa and blue: Agartala.

and theoretical models (Sarker 1967; Grossman and Durran 1984; Oruga and Yoshizaki 1988). During June-September period, mean wind at low levels has a dominant component normal to the orientation of the orography (Rao 1976; Romatschke and Houze 2011; Kumar et al. 2013), and forced ascent of moisture laden air over the mountains produces vertical velocity leading to the formation of clouds and precipitation (Houze 2012). Theory shows that the presence of a mountain with a peak height of $\sim 1 \mathrm{~km}$ causes slow ascent of air even $200 \mathrm{~km}$ upstream, however, higher vertical velocities and lifting of near the surface air occurs mainly over and upstream of the windward side of the orography (Grossman and Durran 1984).

One of the fundamental questions concerning orographic rainfall is nature of the clouds responsible for high seasonal precipitation. A part of the precipitation here results from deep convective clouds embedded in synoptic scale systems, some of which produce a few number of intense rainfall events every year (e.g., station daily rainfall exceeds $200 \mathrm{~mm}$, Francis and Gadgil 2006). Relatively shallow clouds (in the absence of deep convective clouds) giving copious rain are observed over the Western Ghats on many occasions. For example, figure 12.8 in Rao's (1976) monograph shows many raining clouds with their top $<4 \mathrm{~km}$. This feature is also observed in the radar observations near Mahabaleshwar in the Western Ghats (e.g., figures 5 and 6 in Konwar et al. 2014) and in the climatology of vertical section of rain rate derived from the TRMM precipitation radar (PR) measurements (Shrestha et al. 2015). The rapid precipitation formation in warm clouds over the Western Ghats has been hypothesized to a faster rate of condensational growth of droplets in the presence of higher super saturations driven by orographic lifting followed by the collision and coalescence process (Konwar et al. 2014). In the absence of synoptic forcing, a slow rate of ascent of air inside the clouds here allows more time for the collision and coalescence growth process to operate and promotes warm rain formation (Maheskumar 
et al. 2014). Clouds over the Myanmar west coast, in contrast, are observed to be deeper (but their tops are often less than $8 \mathrm{~km}$ high) (Kumar et al. 2013; Shrestha et al. 2015), and rain producing cloud systems are also different (Romatschke et al. 2010).

There is not much information in the literature on the vertical structure of precipitating shallow clouds over the areas influenced by orographic features in south Asia. The main objective of the present study is to understand the vertical structure of precipitating clouds associated with orographic precipitation in south Asia during June-September period. Cumulus congestus clouds coexist with deep convective clouds in a mesoscale convective system (MCS) (Houze 2004), which is embedded in a synoptic scale system. The emphasis in the present study is on precipitating clouds which are most likely not part of deep convective cloud systems. The paper is organized as follows. Section 2 briefly describes the data used and the algorithm employed for identifying precipitating clouds. Section 3 describes the properties of the orographic clouds followed by discussion in section 4 , and section 5 concludes the paper.

\section{Data and methods}

\subsection{Data}

We use the TRMM PR data product 2A25, namely, attenuation corrected equivalent radar reflectivity factor $(Z e)$, a measure of hydrometeor concentration in a cloud. Details about the TRMM orbit and the PR technical specifications can be found in Kummerow et al. (1998). In brief, the PR works in $\mathrm{Ku}$ band ( $2.2 \mathrm{~cm}$ wavelength), horizontal footprint size is $\sim 5 \mathrm{~km} \times 5 \mathrm{~km}$ (after orbit boost in August 2001 which was $4 \mathrm{~km} \times 4 \mathrm{~km}$ when the TRMM was launched in 1997) and the vertical resolution is $250 \mathrm{~m}$. The PR consists of 49 beams with the nearest beams separated by $0.71^{\circ}$ giving a maximum scan angle of $17^{\circ}$ about the central beam. There are 80 vertical levels, the lowest being the Earth ellipsoid, and height is measured with respect to the lowest level. The minimum sensitivity of the $\mathrm{PR}$ is $\sim 17 \mathrm{dBZ}$ (Kummerow et al. 1998). It is normal to distinguish condensed water in liquid form in clouds as cloud liquid water (CLW, liquid water contained in drops that are small and carried with the cloud air) and precipitation liquid water (PLW, made up of drops that have an appreciable fall speed towards Earth) (Houze 1993). The PR, by design, detects PLW and not CLW.

Dryness of the mid-troposphere adversely affects the vertical growth of convective clouds (Sherwood et al. 2004) and could be a factor in causing regional differences in cloud characteristics. Here we have preferred the humidity field measured by radiosondes over the reanalysis data products. Analysis of the data collected with high vertical resolution radiosondes reveal frequent presence of sharp but thin temperature inversions (and dry layers) between 1.5 and $4 \mathrm{~km}$ height over the eastern Arabian Sea and the west coast of India during the summer monsoon season (Bhat 2005, 2006). Coarse vertical resolution of reanalysis data is unable to capture such inversions. Upper air data measured in the months of JulyAugust and spanning 11 years from 2000 to 2010 are taken for Aminidevi (AMN, $\left.11.06^{\circ} \mathrm{N}, 72.15^{\circ} \mathrm{E}\right)$, Mangalore (MNG, $\left.12.30^{\circ} \mathrm{N}, 74.47^{\circ} \mathrm{E}\right)$, Goa (GOA, $15.5^{\circ} \mathrm{N}, 73.83^{\circ} \mathrm{E}$ ) and Agartala (AGAR, $23.5^{\circ} \mathrm{N}$, $\left.91.16^{\circ} \mathrm{E}\right)$; the first is an island in the Arabian Sea, the next two coastal stations on the west coast of India, and the last near the Khasi Hills in northeast India. No upper air stations are nearby or within MC, MM, GT and CM areas. Relative humidity $(\mathrm{RH})$ values of individual soundings are interpolated at $25 \mathrm{hPa}$ interval and then mean and standard deviation are calculated.

\subsection{Identification of precipitating clouds}

For identifying a precipitating cloud of interest from a radar echo, it is normal to prescribe a threshold for $Z e$ at some reference height. Examination of the PR and other radar data reveals that $Z e$ generally increases downwards from cloud top in convective clouds (figure 2), i.e., along the downward trajectory of falling rain drops. Since tops of the shallow clouds are below the zero degree Celsius isotherm (which is typically in 5-6 km altitude range during summer in south Asia), it becomes necessary to select a reference height which is well below the freezing level, however, not so low that it is below the top of mountain ranges. Some peaks in the study area are more than $2500 \mathrm{~m}$ high prescribing a reference height accounting for their presence leaves out many precipitating shallow clouds in other areas. In this study, the reference height selected is $1.5 \mathrm{~km}$, considering a balance between missing some really shallow precipitating clouds vs. sampling tall mountains 


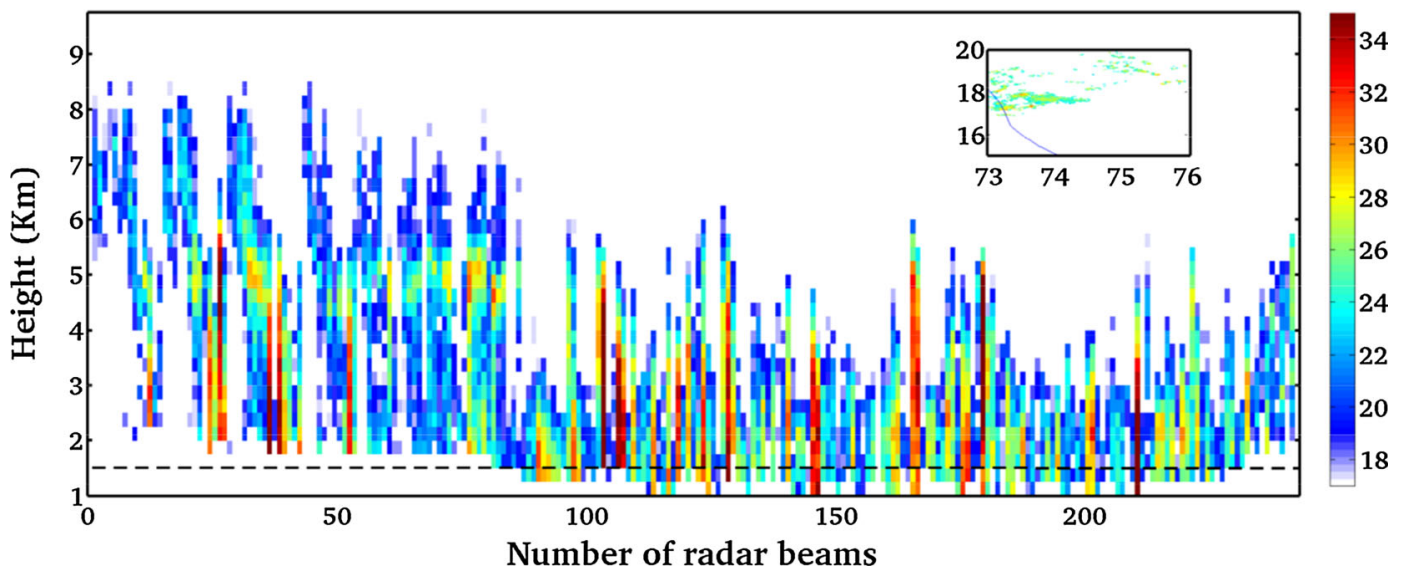

Figure 2. The PR measured vertical profiles of $Z e$ in clouds over the Western Ghats during a TRMM satellite pass. Number along the $\mathrm{x}$-axis refers to individual beam of the PR that detected a cloud within the PR swath area and height corresponds to the distance along the PR beam with respect to the Earth ellipsoid. The dashed line shows $1.5 \mathrm{~km}$ altitude. The PR $2 \mathrm{~A} 25$ product blanks those levels which are below the surface. The colour bar on right shows $Z e$ in dBZ units.

buried in clouds. For the land areas selected for the study (figure 1), fraction of the total area having elevations above $1.5 \mathrm{~km}$ is $0.02 \%, 6.7 \%, 0.05 \%$ and $0 \%$ over $\mathrm{WG}, \mathrm{MM}, \mathrm{KH}$ and $\mathrm{MC}$, respectively. Except for MM, the fractional area cover of mountains taller than $1.5 \mathrm{~km}$ is negligible. It may be noted that those pixels in contact with and below the surface have been flagged in the 2A25 data product and data of these pixels are left out in the analysis.

The $Z e$ threshold at the reference height is set at $30 \mathrm{dBZ}$ which corresponds to a rain rate $(R)$ in the range of $1-10 \mathrm{~mm} \mathrm{hr}^{-1}$ depending on the $Z e-R$ relation selected (Ulbrich and Atlas 1998). For the convenience of reference, we define a cloud with precipitation rate of more than $1 \mathrm{~mm} \mathrm{hr}^{-1}$ as an active precipitating cloud. Distinction between convective and stratiform precipitation is not made in this study.

The maximum echo top height (ETH) is used to classify active precipitating cloud types. Here ETH is defined as the topmost level in a PR beam having a valid signal (i.e., $Z e \geq 17 \mathrm{dBZ}$ ). Note that the actual cloud top height $(\mathrm{CTH})$ will be more, however, there is no way of knowing it from the PR data alone. The TRMM Microwave Imager (TMI) data enables more accurate estimation of $\mathrm{CTH}$, however, there are difficulties in combining the TMI and the PR data. Firstly, the horizontal foot prints of the PR $(5 \mathrm{~km} \times 5 \mathrm{~km})$ and the TMI $(14 \mathrm{~km} \times 5 \mathrm{~km})$ are different. Secondly, the monsoon period is characterized by the presence of multiple cloud layers, which may or may not be connected vertically. The TMI sees upper layers of clouds and thus its data is not suitable to calculate the height of shallow clouds located below. Echoes measured by an X-band radar (which has much higher sensitivity than the PR) over the Mahableshwar region in Western Ghats reveal the presence of shallow clouds whose tops often do not extend more than a kilometer above the $20 \mathrm{dBZ}$ level (Konwar et al. 2014).

The frequency distribution of ETH over some select areas in the south Asia (figure 1) is shown in figure 3. Only those PR beams containing $Z e \geq$ $30 \mathrm{dBZ}$ at $1.5 \mathrm{~km}$ level are included in the analysis. Two distinct types of ETH distributions are seen, those essentially having a single peak between 6 and $7 \mathrm{~km}$, and those having the main peak between 5 and $6 \mathrm{~km}$ and a secondary peak around $3 \mathrm{~km}$. WG and IWC areas belong to the latter category while the remaining areas to the former. The secondary peak over WG area may correspond to precipitating Cumulus congestus clouds. Three types of active precipitating clouds have been defined in this study, namely, shallow echotop cloud (SEC), medium echo-top cloud (MEC), and deep echo-top cloud (DEC) depending on ETH. Ze is at least $30 \mathrm{dBZat} 1.5 \mathrm{~km}$ height in all these clouds. SEC is defined such that its ETH is $\leq 4.5 \mathrm{~km}$. ETH of MEC lies between 4.5 and $8 \mathrm{~km}$, and those clouds with their ETH $>8 \mathrm{~km}$ are called DECs. Cloud lateral dimension equals to that of the PR beam. It is observed from figure 3 that the fraction of SEC is the highest over WG followed by IWC.

SECs and MECs have been extracted from the PR Ze field as follows. Each TRMM pass is scanned 


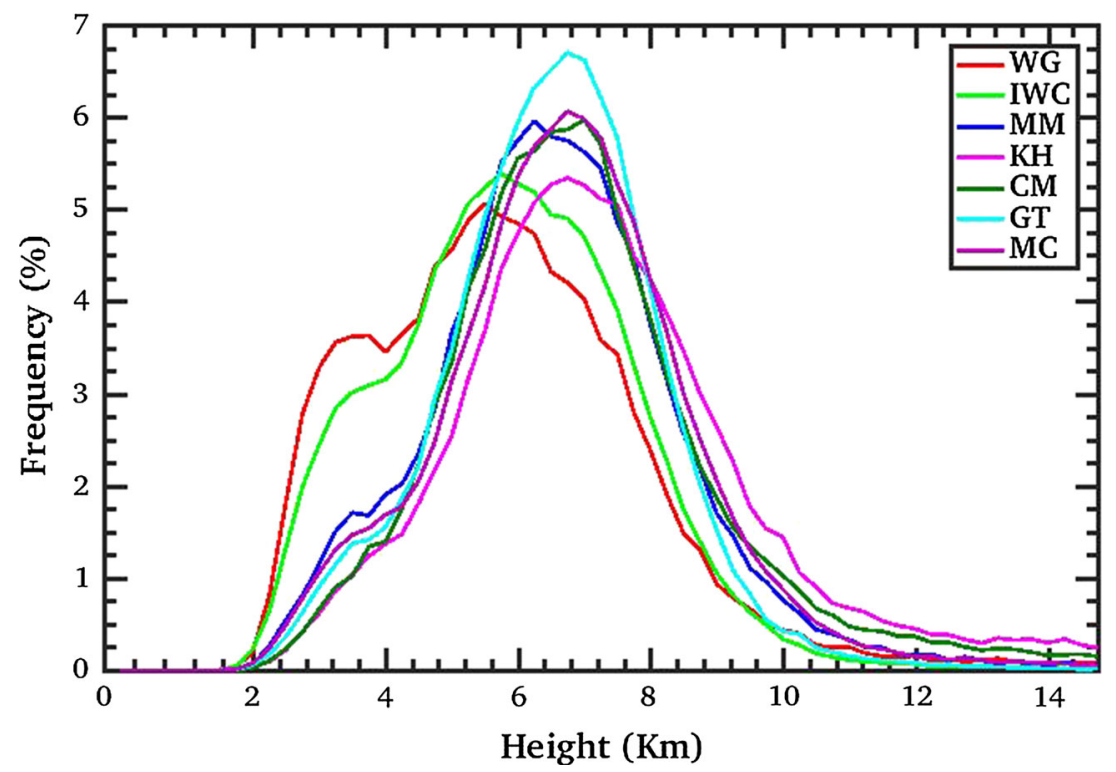

Figure 3. Frequency distribution of cloud echo-top heights of all PR beams having $Z e \geq 30 \mathrm{dBZ}$ at $1.5 \mathrm{~km}$ level.

within the areas selected for the presence of clouds, ETH is obtained for all radar beams having $Z e \geq$ $30 \mathrm{dBZ}$ at $1.5 \mathrm{~km}$ and cloud type is assigned based on ETH. The focus in the present work is on identifying SECs and MECs of orographic origin which form in the absence of a synoptic system. It is normal to see isolated $\mathrm{Cb}$ clouds during the monsoon break period also (perhaps these are forced by local orographic features and diurnal forcing), but their area coverage as well as numbers are small, and they may not evolve into an MCS. Therefore, some allowance has to be made for the presence of DECs in the absence of synoptic scale forcing. We expect the fraction of such clouds to be low. For each TRMM PR pass over the area of interest, fraction (F1) of DECs is calculated from the equation,

$$
\mathrm{F} 1=N_{\mathrm{DEC}} /\left(N_{\mathrm{DEC}}+N_{\mathrm{SEC}}+N_{\mathrm{MEC}}\right)
$$

where $N$ is the number of clouds and the subscript corresponding cloud type. In this study, SECs and MECs of a TRMM pass are included in the analysis if $\mathrm{F} 1 \leq 0.05$.

\section{Results}

Figure 4 shows a vertical section through a SEC over the Western Ghats. Ze exceeds $40 \mathrm{dBZ}$ in a volume of about $1.5 \mathrm{~km}$ thickness whose width is approximately one PR pixel. Such high values of $Z e$ are normally observed in deep convective clouds and storms (Houze et al. 2007; Kumar 2015, 2016).
The overall lateral dimension of the cloud is about $20 \mathrm{~km}$ which is $\sim 4 \mathrm{PR}$ pixels, i.e., not very different from that of roll clouds reported over the Arabian Sea (Rao 1976). However, it is not clear if the section seen in figure 4 is that of a roll cloud or of numerous cumulus congestus clouds aligned parallel to the mountain range. When one flies over WG during the summer monsoon season, convective clouds lined up parallel to the mountain range are observed and their spatial extent normal to the mountain range is rather narrow. Here vigorously growing, densely spaced numerous individual cumulus congestus clouds are present. A PR pixel is most likely to contain several such congestus clouds. Therefore, spatial contiguity in the PR data is no proof that they are part of a larger cloud type.

Figure 5 shows the spatial distribution of the number of SECs in each $1^{\circ} \times 1^{\circ}$ area. The highest occurrence of SECs is over the WG, with some areas more prone than others within the Ghats region. The IWC adjacent to the WG and the MM area are also favourite areas for SECs. Note that although the orography has a profound influence on the seasonal precipitation over $\mathrm{KH}$, the number of SECs is very small there. Same is the case with CM off the GT (figure 1). This becomes more clear when we examine the frequency distribution of ETHs over the seven areas selected (figure 6). The difference between figures 3 and 6 is that in the latter, clouds observed when $\mathrm{F} 1 \leq 0.05$ are only included. In figure $6, \mathrm{WG}$ and IWC show a single peak between 3 and $4 \mathrm{~km}$, MM nearly a flat distribution between 3 and $6 \mathrm{~km}$ while the mode is 


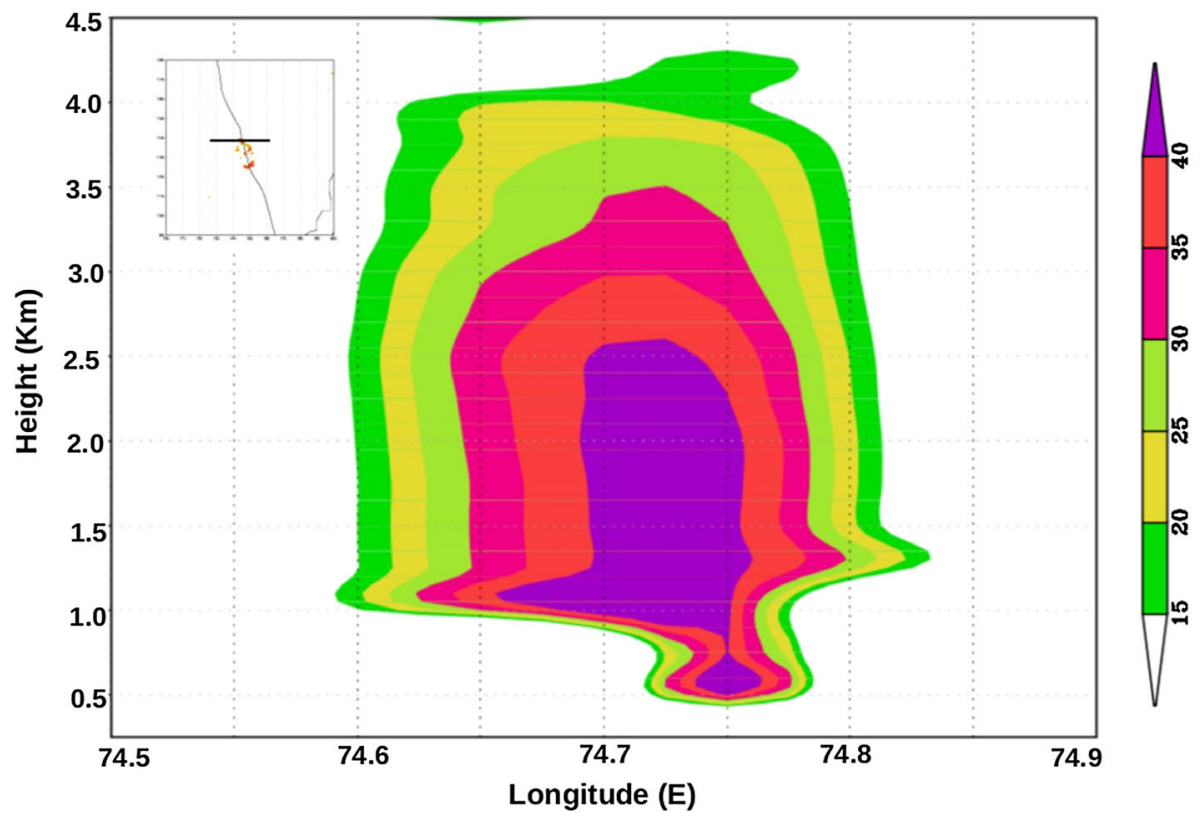

Figure 4. Vertical section through a shallow echo-top cloud near the Western Ghats observed on 23 July 2002 . Section is taken along $13.1^{\circ} \mathrm{N}$ latitude (inset) and plotted against longitude and height. Colour-bar shows $Z e$ in dBZ unit.
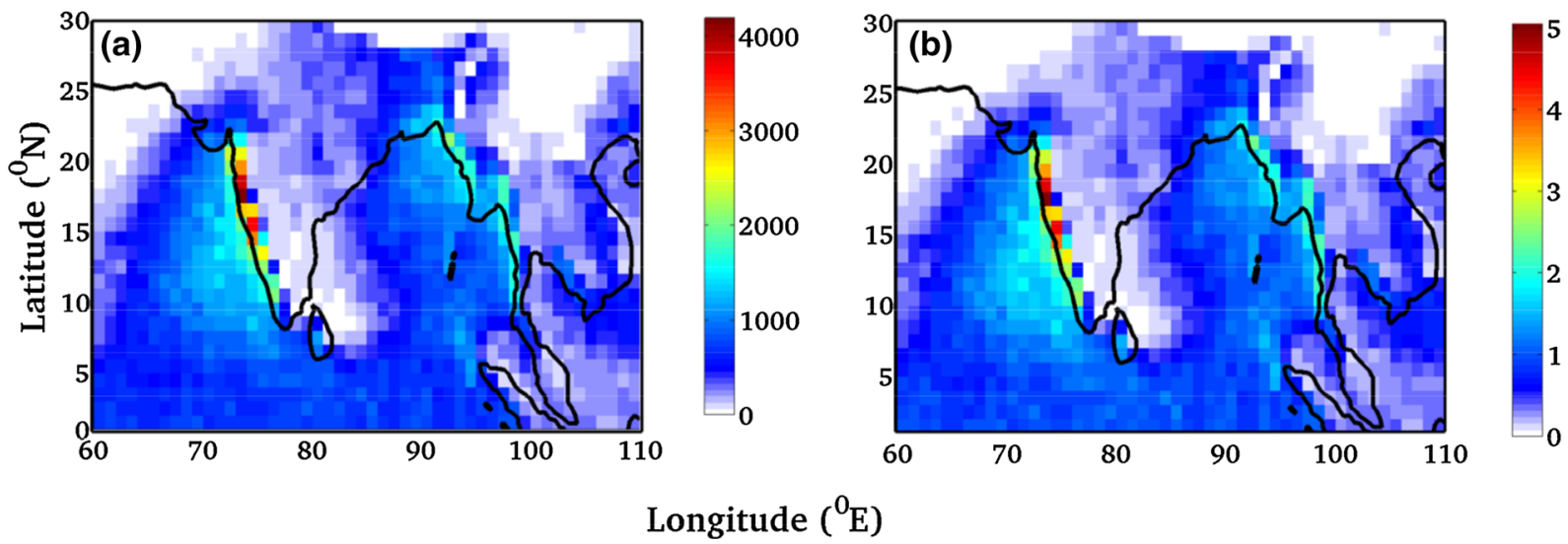

Figure 5. Spatial distribution of (a) total number of radar beams with echo top height $\leq 4.5 \mathrm{~km}$ per $1^{\circ} \times 1^{\circ}$ area, and $(\mathbf{b})$ the total numbers in the left panel normalized by the number of TRMM passes during the study period. Western Ghats shows the highest fraction of shallow echo-top clouds compared to other areas.

between 5 and $6 \mathrm{~km}$ over other areas. There is close similarity between $\mathrm{KH}$ and $\mathrm{CM}$ in the distribution of ETHs.

Average vertical profiles of $Z e$ in SECs and MECs are shown in figure 7(a). It is observed from figure 7(a) that vertical profiles of $Z e$ in SECs in different areas are almost identical. $Z e$ (in $\mathrm{dBZ}$ units) in SECs increases almost linearly with distance from echo-top towards the surface between 4.5 and $2 \mathrm{~km}$, peaks around $1.5 \mathrm{~km}$ (maximum average $Z e \sim 33 \mathrm{dBZ}$ ) and then shows a decreasing trend towards the surface (MM happens to be a lone exception). The average profiles of MECs are also nearly identical; however, there are minor but important differences. KH shows a larger slope around $5 \mathrm{~km}$ altitude. A similar behaviour, but at a lower level $(\sim 4.5 \mathrm{~km})$ is observed in the profiles of CM and GT. This occurs around the zero degree Celsius level suggesting that ice physics is playing a role here. It may be noted that shape of $Z e$ profile is related to cloud microphysical processes and in-cloud vertical velocity (Heymsfield et al. 2010). Above the freezing level, ice cloud microphysical processes promote rapid growth of hydrometeors and tend to increase $Z e$ with height, whereas, change from liquid to ice phase decreases Ze owing to the decrease in the complex refractive index of water from 0.93 for liquid phase to 0.2 for ice phase 


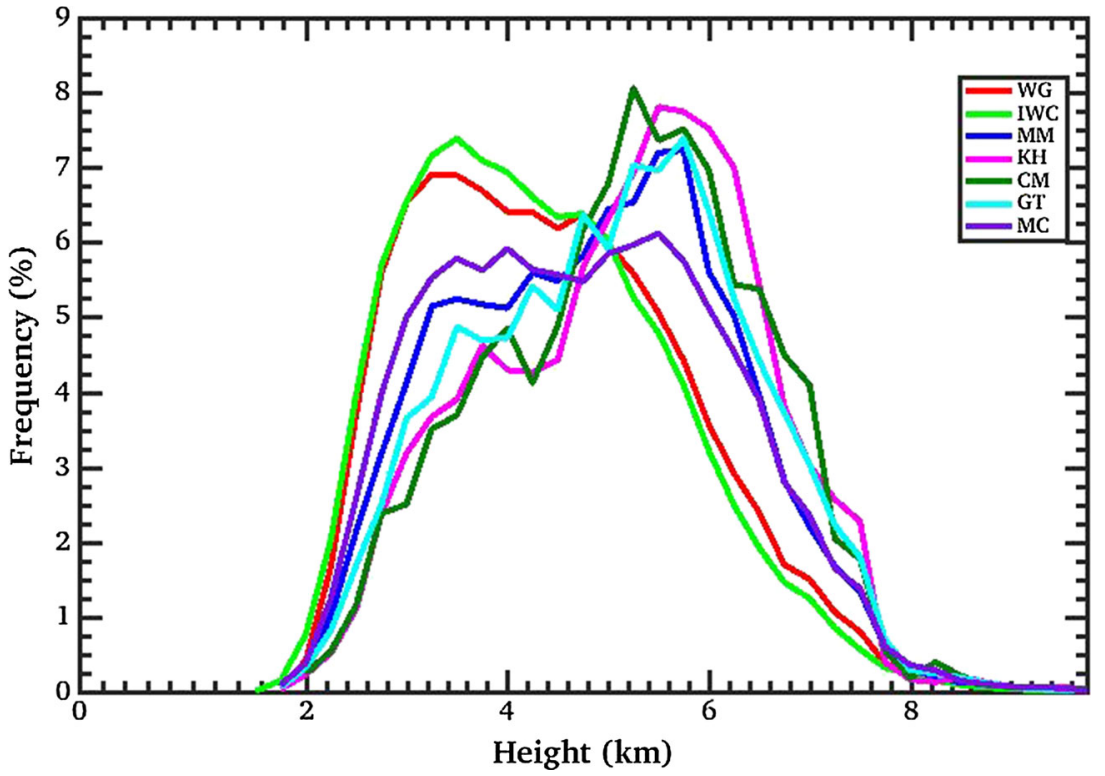

Figure 6. Frequency distribution of cloud echo-top heights with $Z e \geq 30 \mathrm{dBZ}$ at $1.5 \mathrm{~km}$ and F1 $\leq 0.05$.
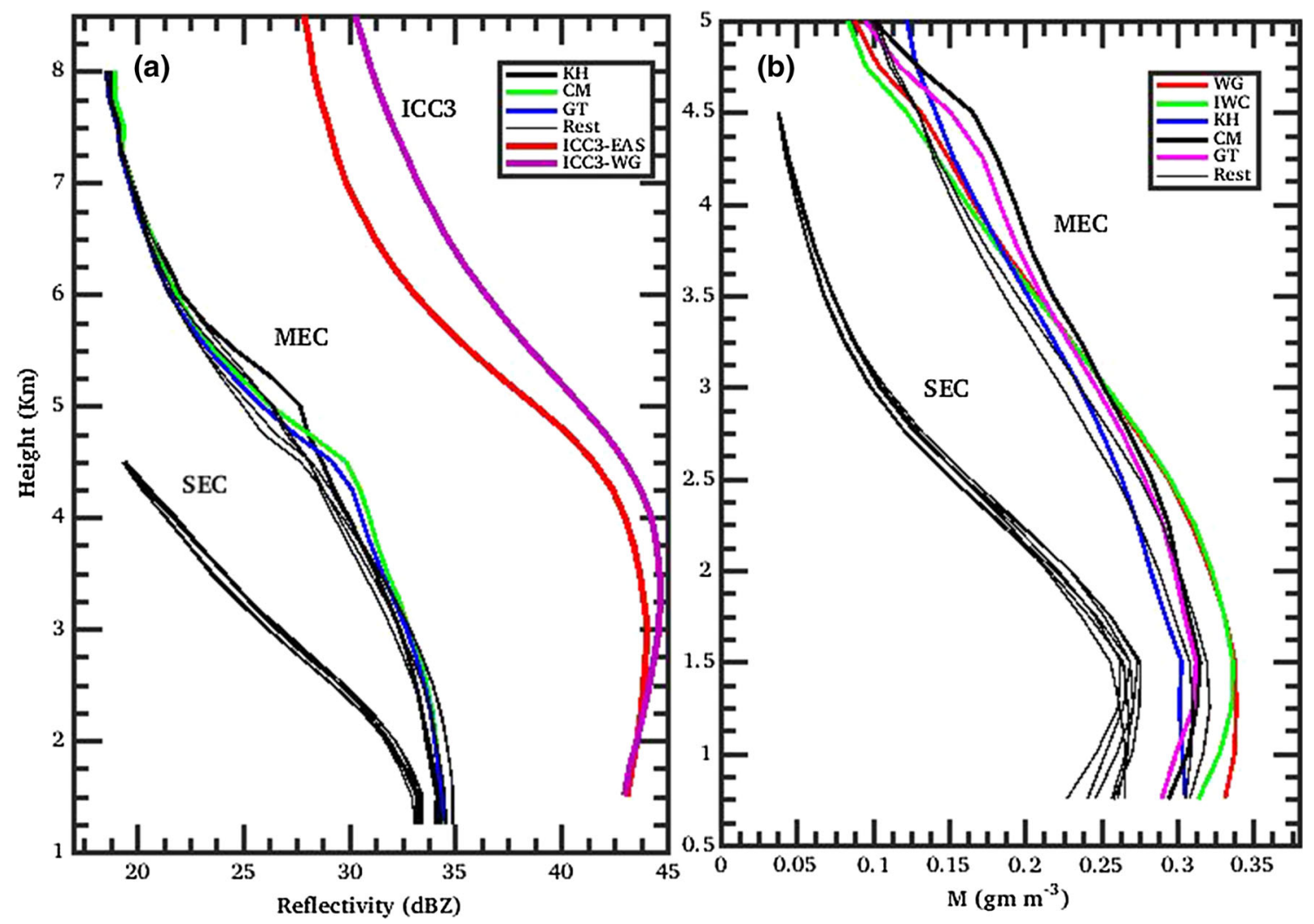

Figure 7. Average vertical profiles of $Z e$ (left) and precipitation liquid water M (right) in SECs and MECs. In panel (a), vertical profiles of intense convective clouds (ICC3) which are cumulonimbus clouds in mature phase (see Bhat and Kumar 2015) are included for comparison. Profiles that stand out from the rest have been identified. Differences among the profiles of SECs are small and in view of this, same colour line is used for all geographic areas. For ICC3, EAS: Eastern Arabian Sea, WG: Western Ghats.

(Fabry and Zawadzki 1995). Falling hydrometeors grow along their downward trajectory by the collision-coalescence mechanism which increases
Ze while breakup and fallout of hydrometeors decrease $Z e$ locally. Higher vertical velocity helps in retaining (relatively) bigger hydrometeors and 
thus a larger $Z e$. Below cloud base, evaporation and breakup of hydrometeors decrease $Z e$. In the case of SEC, hydrometeors are expected to grow by the collision-coalescence mechanism. Average $Z e$ profiles of SECs being so similar in different areas suggests close similarity in cloud microphysical processes as well as in-cloud vertical velocities. In the case of MECs too, peak in the average $Z e$ occurs between 1 and $1.5 \mathrm{~km}$ and lies in $34-35 \mathrm{dBZ}$ range. Also shown in figure $7(\mathrm{a})$ is vertical profiles of intense convective clouds (ICC3) over the Arabian Sea and Western Ghats area (Bhat and Kumar 2015) to facilitate a comparison of SECs and MECs with $\mathrm{Cb}$ clouds. ICC3 is an active $\mathrm{Cb}$ cloud in mature phase and belongs to the top $5 \% \mathrm{Ze}$ population at $3 \mathrm{~km}$ altitude (see Bhat and Kumar 2015 and Kumar and Bhat 2016 for further details). $\mathrm{An}$ active $\mathrm{Cb}$ cloud has much higher hydrometeor concentration compared to MECs, peak $Z e$ occurs between 3 and $4 \mathrm{~km}$ and shows a rapid decrease with height between $5 \mathrm{~km}$ and $6 \mathrm{~km}$. Ze in ICC3 clouds is $7-10 \mathrm{dBZ}$ higher at all levels compared to MECs. It is interesting to note that above $2 \mathrm{~km}$ altitude, $Z e$ values of MECs are much higher compared to that of the SECs implying the advantage of deeper cloud depth in the growth of hydrometeors. (Basically a deeper cloud allows more time and a longer path length for hydrometeors to grow via the collision-coalescence mechanism.) However, the difference between the two narrows down to $\sim 1.5 \mathrm{dBZ}$ at $1.5 \mathrm{~km}$ suggesting a relatively faster precipitation accumulation in SECs compared to MECs nearer to the cloud base.

$Z e$, proportional to $\sum \mathrm{D}_{\mathrm{i}}^{6}\left[\mathrm{D}_{\mathrm{i}}\right.$ being the diameter of the hydrometeors present in the radar sampling volume (Houze 1993)], is a proxy for the hydrometeor concentration. Often, rain rate and the amount of precipitation liquid water per unit volume (M) are of interest to meteorologists. Here we briefly examine how $\mathrm{M}$ evolves with altitude in SECs and MECs. M (proportional to the 3rd moment of the drop diameter) and $Z e$ have been empirically related by an equation of the form, $\mathrm{M}=\mathrm{c} Z e^{\mathrm{d}}$, where $Z e$ is in $\mathrm{mm}^{6} \mathrm{~m}^{-3}$ units and $\mathrm{M}$ in $\mathrm{gm} \mathrm{m}^{-3}$ (Green and Clark 1972). Values of $\mathrm{c}$ and $\mathrm{d}$ depend on the cloud drop size distribution and Green and Clark (1972) assigned values of 0.00344 and 0.57 to c and d, respectively, based on in situ cloud measurements made from an aircraft (Marshall et al. 1948). Values of M have been calculated assigning the above values for $\mathrm{c}$ and $\mathrm{d}$, and figure $7(\mathrm{~b})$ shows the average vertical profiles of $\mathrm{M}$ for SECs and MECs. (Values of $\mathrm{c}$ and $\mathrm{d}$ used here are valid for liquid phase only, and therefore $\mathrm{M}$ is shown up to $5 \mathrm{~km}$ height.) It is observed from figure 7(b) that $\mathrm{M}$ increases from cloud top towards the cloud base, and $M$ peaks around $1.5 \mathrm{~km}$ altitude. The increase in $\mathrm{M}$ downwards is owing to growth of falling cloud drops. During the cloud growth phase, drop (droplet) sizes are small and condensed water is carried up in the updraft. Below the freezing level, droplets grow along their upward journey by condensation and collision-coalescence mechanism (Houze 1993). When hydrometeor size reaches a threshold where its terminal velocity exceeds updraft speed, it starts falling down. Along the downward trajectory, its size increases further by the collision-coalescence mechanism, and PLW increases at the expense of CLW. This mechanism makes $Z e$ to increase downwards along the drop trajectory since $Z e$ is proportional to the 6 th power of drop size (Houze 1993). The terminal velocity increases with drop size (Beard and Pruppacher 1969), and the average profile of $Z e$ reflects a balance between growth of drops by cloud microphysical processes $v s$. removal by their fall out at different heights. The decrease of $\mathrm{M}$ below $1.5 \mathrm{~km}$ altitude in figure $7(\mathrm{~b})$ may be due to the faster removal of hydrometeors and break up of larger drops.

The average profiles in figure 7 (a) do not reflect the range of $Z e$ values observed at different levels over different areas. Contoured frequency by altitude diagram (CFAD) (Yuter and Houze 1995) is a compact way of representing $Z e$ variations at different heights. CFAD shows (relative) probability of finding a given radar echo range in clouds at each altitude. CFAD is obtained as follows. The number of occurrences of reflectivity between 17 and $60 \mathrm{dBZ}$ in each $2.5 \mathrm{dBZ}$ interval at each $0.25 \mathrm{~km}$ altitude interval between 0.25 and $8 \mathrm{~km}$ altitude has been counted and then normalized by the maximum number of occurrences among the vertical levels. Also the total number of occurrences of $Z e \geq 17 \mathrm{dBZ}$ at each level is counted. A vertical level is not included if the total number of occurrences there is $<10 \%$ of the maximum among all levels. Figure 8 shows CFADs of SECs and MECs. All the CFADs in figure 8 show maximum probability at $1.5 \mathrm{~km}$ height and $Z e \sim 30 \mathrm{dBZ}$ since by definition, all SECs and MECs have this combination of height and $Z e$. Mode of reflectivity decreases above $1.5 \mathrm{~km}$ altitude and regional differences are small for SECs. CFADs of MECs show regional differences with Western Ghats and Arabian Sea showing higher fraction of reflectivity between 1.5 and $4 \mathrm{~km}$ altitude range compared to other areas. 

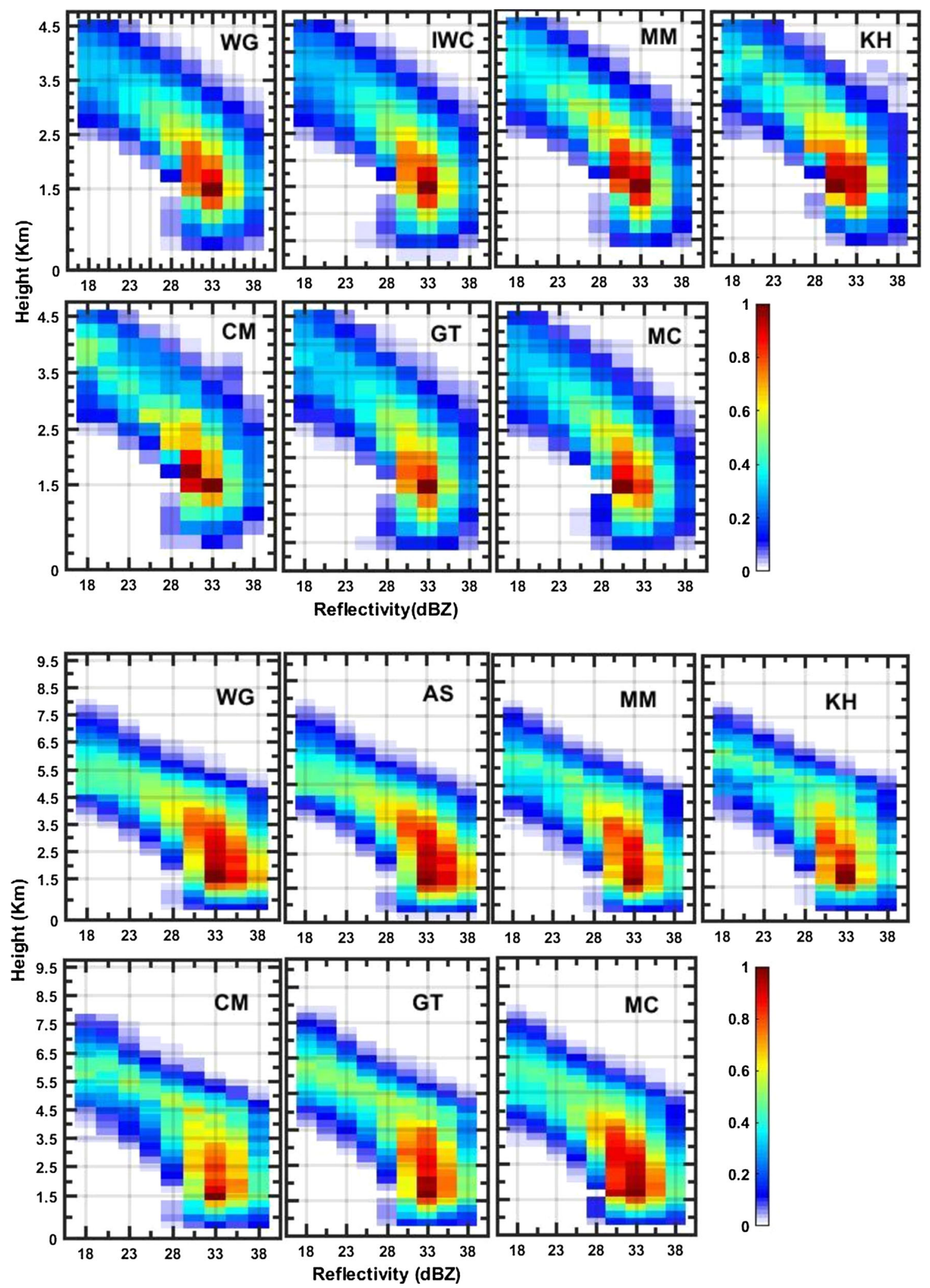

Figure 8. Contoured frequency by altitude diagram showing the relative frequency of occurrence of $Z e$ in precipitating orographic clouds. Top panel, SEC; bottom panel, MEC. The colour bars show the relative frequency. 

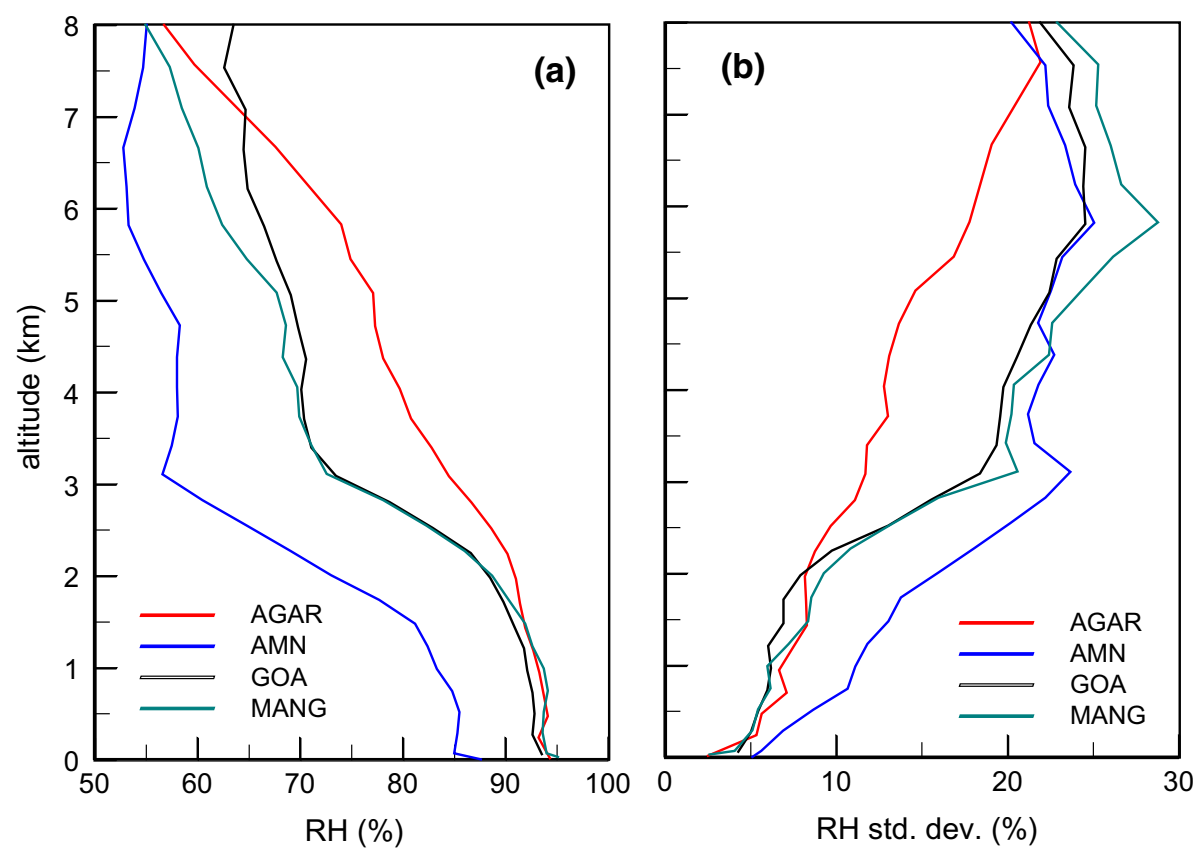

Figure 9. Vertical profiles of average relative humidity (left), and its standard deviation (right). AGAR: Agartala; AMN: Aminidevi; MANG: Manglore; and GOA: Goa. Agartala is near the Khasi Hills, and the other three stations are close to IWC and WG areas. The mid-troposphere over Amini Devi is dry, while Goa and Mangalore are drier compared to Agartala.

\section{Discussion}

The Western Ghats area has the highest frequency of occurrence of SECs (figure 5) and the mode of ETH lies between 3 and $4 \mathrm{~km}$ over the Western Ghats and Indian West Coast, whereas the modal height is around $6 \mathrm{~km}$ over other areas. What is responsible for this difference? One reason could be mid-tropospheric dryness. As moist air ascends in clouds, it entrains surrounding environmental air (Blyth et al. 1988). Environmental air is usually unsaturated and some CLW evaporates to make the cloud-environment air mixture saturated. In a drier environment, more CLW gets evaporated when entrainment occurs and cloud dissipates at a lower height if other conditions are equal to start with.

Figure 9 shows vertical profiles of average relative humidity $(\mathrm{RH})$ and its standard deviation during July-August months. Among the stations, Aminidevi has the lowest $\mathrm{RH}$ near the surface, but its value is not really low and around $85 \%$, which is typical of marine conditions in summer (Bhat 2006). AGAR, GOA and MNG have much higher surface RH (i.e., 94\%), and humidity conditions at these stations are almost identical in the lowest $1.5 \mathrm{~km}$. Between 3 and $6 \mathrm{~km}$, average $\mathrm{RH}$ is lowest at AMN and highest at AGAR, GOA and MNG lie in between. The highest standard deviation of $\mathrm{RH}$ in the mid-troposphere is observed at AMN, MNG and GOA with a value of more than $20 \%$. Mid-troposphere over AGAR is characterized by high average $\mathrm{RH}$ and low standard deviation, i.e., lower and mid-troposphere remain moist most of the time here. Higher standard deviation means larger amplitude of temporal fluctuations about the mean. Normally mid-troposphere becomes more moist when monsoon is active (Bhat et al. 2002). A higher standard deviation in RH over IWC and WG areas means that during periods when the monsoon is not active, the mid-troposphere is dry, thus limiting the vertical extent of orographic clouds. Basically, the Arabian Sea is surrounded by deserts to its west and north. During the summer monsoon season, marine air at lower levels is capped by dry and warm air of desert origin that move eastward, and dry mid-troposphere and atmospheric inversions below the freezing level are frequent over here (Ghosh et al. 1978; Bhat 2002, 2006; Maheskumar et al. 2014). The other areas considered in this study are far away from dry areas and strong atmospheric inversions are unlikely, and therefore clouds have larger vertical extent. What limits their ETH preferably to around $6 \mathrm{~km}$ is not clear. 


\section{Conclusions}

The main conclusions of this study are the following:

- The Western Ghats has the highest occurrence of shallow echo-top clouds followed by eastern Arabian Sea and Myanmar west coast. Number of shallow echo-top clouds are less over Khasi Hills and Cardamom mountains.

- Average vertical profiles of shallow echo-top clouds are nearly identical over different areas while medium echo-top clouds show some differences around the freezing level and below $3 \mathrm{~km}$ altitude. Among the different areas considered, Khasi Hills area has the largest slope of MECs around $5 \mathrm{~km}$ height.

- Among the medium echo-top clouds, those over the Western Ghats and the eastern Arabian Sea contain higher amounts of precipitation liquid water below $3 \mathrm{~km}$ altitude.

- Western Ghats and Cherapunji regions have different humidity structures and this could be a reason for the cloud echo-top height differences between these regions.

\section{Acknowledgements}

This work was supported by grants from the Department of Science and Technology, New Delhi, and the Ministry of Earth Sciences, New Delhi. TRMM data are provided by NASA's Earth-Sun System Division. The radiosonde data used in the work were taken by the India Meteorological Department and downloaded from the University of Wyoming website.

\section{References}

Beard K V and Pruppacher H R 1969 A determination of the terminal velocity and drag of small water drops by means of a wind tunnel; J. Atmos. Sci. 26 1066-1072.

Blyth A M, Cooper W A and Jensen J B 1988 A study of the source of entrained air in Montana cumuli. J. Atmos. Sci. 45(24) 3944-3964.

Bhat G S 2002 Near surface variations and surface fluxes over the North Bay of Bengal during the 1999 Indian Summer Monsoon; J. Geophys. Res. Atmos. 107 4336, https://doi. org/10.1029/2001JD000382.

Bhat G S 2005 Convection inhibition energy of the inversion and the suppressed rainfall over the Arabian Sea during July 2002: Mausam (ARMEX Special Issue) 56 89-96.

Bhat G S 2006 The Indian drought of 2002 - a subseasonal phenomenon?; Quart. J. Roy. Meteorol. Soc. 132 2583-2602.
Bhat G S, Chakraborthy A, Nanjundaiah R S and Srinivasan J 2002 Vertical thermal structure of the atmosphere during active and weak phases of convection over the north Bay of Bengal: Observation and model results; Curr. Sci. 83 296-302.

Bhat G S and Kumar S 2015 Vertical structure of cumulonimbus towers and intense convective clouds over the South Asian region during the summer monsoon season; J. Geophys. Res. Atmos. 120, https://doi.org/10.1002/ 2014JD022552.

Fabry F and Zawadzki I 1995 Long-term radar observations of the melting layer of precipitation and their interpretation; J. Atmos. Sci. 52 838-851.

Francis P A and Gadgil S 2006 Intense rainfall events over the west coast of India; Meteorol. Atmos. Phys. 94 27-42, https://doi.org/10.1007/s00703-005-0167-2.

Ghosh S K Pant M C and Dewan B N 1978 Influence of the Arabian Sea on the Indian summer monsoon; Tellus 30 117-125.

Green D R and Clark R A 1972 Vertically integrated liquid water - a new analysis tool; Mon. Wea. Rev. 100 548552.

Grossman R L and Durran D R 1984 Interaction of low level flow with Western Ghat mountains and offshore convection in the summer monsoon; Mon. Wea. Rev. 112 $652-672$.

Heymsfield G M, Tian L, Heymsfield A J, Li L and Guimond S 2010 Characteristics of deep tropical and subtropical convection from nadir-viewing high-altitude airborne Doppler radar; J. Atmos. Sci. 67 285-308.

Houze R A 1993 Cloud dynamics; Academic Press, 496p.

Houze R A 2004 Mesoscale convective systems; Rev. Geophys. 42, https://doi.org/10.1029/2004RG000150.

Houze R A Jr, Wilton D C and Smull F B 2007 Monsoon convection in the Himalayan region as seen by the TRMM precipitation radar; Quart. J. Roy. Meteorol. Soc. 133 1389-1411.

Houze R A 2012 Orographic effects on precipitating clouds; Rev. Geophys. 50 RG1001, https://doi.org/10. 1029/2011RG000365.

Houze R A, Rasmussen K L, Zuluaga M D and Brodzik S R 2015 The variable nature of convection in the tropics and subtropics: A legacy of 16 years of the Tropical Rainfall Measuring Mission satellite; Rev. Geophys. 53, https:// doi.org/10.1002/2015RG000488.

Konwar M, Das S K, Deshpande S M, Chakravarty K and Goswami B N 2014 Microphysics of clouds and rain over the Western Ghat; J. Geophys. Res. Atmos. 119, https:// doi.org/10.1002/2014JD021606.

Kumar S, Hazra A and Goswami B N 2013 Role of interaction between dynamics, thermodynamics and cloud microphysics on summer monsoon precipitating clouds over the Myanmar Coast and the Western Ghats; Clim. Dyn. https://doi.org/10.1007/s00382-013-1909-3.

Kumar S and Bhat G S 2016 Vertical profiles of radar reflectivity factor in intense convective clouds in the tropics; J. Appl. Meteorol. Climatol. 55(5) 1277-1286.

Kumar S 2015 A 10-year climatology of vertical properties of most active convective clouds over the Indian regions using TRMM PR; Theor. Appl. Climatol. 127(1-2) 429 440, https://doi.org/10.1007/s00704-015-1641-5. 
Kumar S 2016 Three dimensional characteristics of precipitating cloud systems observed during Indian summer monsoon; Adv. Space Res. 58(6) 1017-1032.

Kummerow C, Barnes W, Kozu T, Shiue J and Simpson J 1998 The Tropical Rainfall Measuring Mission (TRMM) sensor package; J. Atmos. Oceanic. Technol. 15 809-817.

Marshall J S and Palmer W Mc K 1948 The distribution of raindrops with size; J. Meteorol. 5(4) 165-166.

Maheskumar R S, Narkhedkar S G, Morwal S B, Padmakumari B, Kothawale D R, Joshi R R, Deshpande C G, Bhalwankar R V and Kulkarni J R 2014 Mechanism of high rainfall over the Indian west coast region during the monsoon season; Clim. Dyn. 43(5-6) 1513-1529.

Mukherjee A K, Rao M K and Shah K C 1978 Vortices embedded in the trough of low pressure off MaharashtraGoa coasts during the month of July; Indian J. Met. Hydrol. Geophys. 29 61-65.

Oruga Y and Yoshizaki M 1988 Numerical study of orographic-convective precipitation over eastern Arabian Sea and the Ghat mountains during the summer monsoon; J. Atmos. Sci. 45 2097-2121.

Rao Y P 1976 Southwest monsoon; India Meteorological Department.

Romatschke U, Medina S and Houze R A 2010 Regional, seasonal, and diurnal variations of extreme convection in the south Asian region; J. Clim. 23 419-439
Romatschke U and Houze R A Jr 2011 Characteristics of precipitating convective systems in the south Asian monsoon; J. Hydrometeorol. 12 3-26.

Sarker R P 1967 Some modification in a dynamical model of orographic rainfall; Mon. Wea. Rev. 95 673-684.

Sherwood S C, Minnis P and McGill M 2004 Deep convective cloud-top heights and their thermodynamic control during crystal-face; J. Geophys. Res. 109, https://doi.org/ 10.1029/2004JD004811.

Shrestha D, Deshar R and Nakamura K 2015 Characteristics of summer precipitation around the Western Ghats and the Myanmar West Coast; Int. J. Atmos. Sci., https:// doi.org/10.1155/2015/206016.

Ulbrich C W and Atlas D 1998 Rainfall microphysics and radar properties: Analysis methods for drop size spectra; J. Appl. Meteor. 37 912-923.

Xie $\mathrm{S}$ P, Xu H, Saji N H, Wang $\mathrm{Y}$ and Liu W T 2006 Role of narrow mountains in large-scale organization of Asian monsoon convection; J. Clim. 19(14) 3420-3429.

Yuter S E and Houze R A Jr 1995 Three-dimensional kinematic and microphysical evolution of Florida cumulonimbus: Part II. Frequency distribution of vertical velocity, reflectivity, and the differential reflectivity; Mon. Wea. Rev. 123 1941-1963. 